\title{
Understanding How IT Capability Impacts Sustainable Competitive Advantage through Business Process
}

\section{Management}

\author{
Devika Nadarajah (Corresponding Author) \\ Putra Business School, 43400 Serdang, Selangor, Malaysia \\ Tel: 603-9769-1790Ｅ-mail: devika@putrabs.edu.my \\ Sharifah Latifah Syed Abdul Kadir \\ Faculty of Business and Accountancy, University Malaya \\ 58100 Kuala Lumpur, Malaysia \\ Haliyana Khalid \\ Universiti Teknologi Malaysia, Jalan Sultan Yahya Petra, \\ 54100 Kuala Lumpur, Malaysia \\ Tel: 603-2180-5069Ｅ-mail: haliyana@ibs.utm.my
}

Received: November 1, 2019 Accepted: November 12, 2019 Published: November 25, 2019 doi:10.5296/bms.v10i2.15899 URL: https://doi.org/10.5296/bms.v10i2.15899

\begin{abstract}
Business Process Management or BPM is the blueprint of how work is performed in any organisation to deliver customer requirements. Sustainable Competitive Advantage or SCA pushes organisations to adopt flexibility and dynamism into their systems, processes and culture. A study was carried out to determine the influence of BPM on SCA, and to identify the antecedents of BPM in creating SCA. One of the antecedents' of the study was IT capability. The study was based on organisations in Malaysia. The results from the study revealed that IT capability failed to observe significant relationship to BPM and SCA. In an attempt to understand further this phenomenon, a series of interviews were carried out on 3
\end{abstract}


companies representing the telecommunications, consulting and manufacturing industries. The findings revealed that while IT capability is a "must-have", there are numerous factors that may influence or hinder the effectiveness of IT capability implementation.

Keywords: Business Process Management, IT Capability, Sustainable Competitive Advantage

\section{Introduction}

The highly volatile business environment and the global reach of organisations today have evoked a new era of delivering customer requirements. People, processes, and systems have evolved to cater to current demands. In this endeavour, the effective management and improvement of processes and the capability of available systems aid employees in executing their operational activities efficiently. These elements come together to provide organisations with the ability to compete and stay ahead of the competition.

This paper presents a study on Business Process Management (BPM) and Sustainable Competitive Advantage (SCA) in the Malaysian context. BPM is a combination of Total Quality Management (TQM) principles and Business Process Re-engineering (BPR) activities. SCA, on the other hand, reflects the ability of organisations to develop core competencies that are difficult for competitors to duplicate over a long period of time.

The research interest was to explore the mediating effect of BPM on the relationship between IT Capability and SCA. Past research has examined the influence of IT Capability on SCA with inconsistent results (Law \& Ngai (2007); Lepments et al. (2012) and Stoel \& Muhanna, (2009)). This mooted the need to investigate the relationship between IT Capability and SCA in the context of BPM, as per Nadarajah and Kadir's (2014) suggestion. This study is grounded in the dynamic capability theory, which is an extension of the resource-based theory that focuses on the internal capabilities of organisations that contribute towards agility and competence. In this respect, BPM is an internal capability believed to be able to deliver SCA. In addition, IT Capability, a concept derived from technology-fit theory, is introduced as a predictor of BPM, whereby it is posited to enhance the effectiveness of BPM in delivering SCA. This research and its findings, particularly its quantitative findings, are important to practitioners. It was discovered from this study that a significant relationship exists between BPM and SCA. However, IT Capability was found to have no significant effect on BPM and SCA.

Organisations spend considerable amounts of money on building IT Capability for the purpose of staying competitive and gaining competitive advantage. Therefore, when the quantitative results revealed no significant relationship between these constructs, a follow-up qualitative study was conducted to examine why IT Capability failed to influence BPM and SCA. This qualitative research was able to shed light on the best approaches to building IT Capability that enhance BPM and SCA. The subsequent sections of this paper provide a discussion of both the quantitative and qualitative stages of the research. 


\section{Review of Literature}

\subsection{BPM}

BPM is the blueprint of any organisation. It documents how work is executed in order to deliver customer requirements. BPM in the past was a central focus in the manufacturing industry; however today, it has proved relevant even in the services industry (Paim et al., 2008). Organisations' strategies, structures, and systems are translated into their work processes. For this reason, no two organisations, even in the same industry, share identical processes. In today's environment, process management and improvement initiatives are seen as means of creating competitiveness (Goldkuhl \& Lind, 2008; Lee \& Dale, 1998; Zairi, 1997). This research views BPM within the perspectives of Business Process Orientation (BPO) (McCormack, 2001) and Process Improvement Initiatives (PII) to create a holistic view of BPM, encompassing its management aspects as well as its improvement aspects (Goldkuhl \& Lind, 2008; Lee \& Dale, 1998; Nadarajah \& Kadir, 2016; Zairi, 1997). Past research on BPM has primarily been concerned with its effect on organisational performance. While it is imperative to understand the relationship of BPM to organisational performance, it remains an after fact. The organisation has already achieved its performance, so determining the relationship between BPM and organisational performance only proves theoretical relevance. In this research, the effect of BPM on SCA is important not only for theory but also for practice. As SCA is about developing competitive advantage, it is crucial to determine if BPM is an enabler of competitiveness. This will allow practitioners to justify the need to allocate sufficient resources towards the placement of efficient and effective processes.

\section{$2.2 S C A$}

Due to the height of competition, organisations worry not only about increasing current market share but also about sustaining their market share over a long period of time. SCA pushes organisations to adopt flexibility and dynamism, and is achieved when an organisation's rivals are unable to duplicate its strategies now or even in the future (Barney, 1991; Chaharbaghi \& Lynch, 1999; Rijamampianina et al., 2003). Key attributes of SCA are value, rareness, inimitability, and non-substitutability (Barney, 1991). The dynamic capability theory advocates that competitive advantage can be achieved through well-developed internal capabilities and agility. This study examined BPM as a source of internal capability worthy of creating competitive advantage and IT Capability as a mechanism to enhance the effectiveness of BPM. An effective process can achieve greater efficiency once it is automated; therefore, IT Capability's influence on organisational competitiveness is believed to be through BPM (Porter, 1985).

\subsection{IT Capability}

IT Capability is broadly understood as the mechanism through which IT resources are capitalised on to deliver customer requirements (Bharadwaj, 2000). IT Capability does not stand alone; instead, it works in unison with other resources in an organisation. IT Capability 
assists in increasing organisational efficiency by providing automating capabilities that can dramatically reduce cycle times (Liu et al., 2008). As such, IT Capability can influence the effectiveness of BPM in executing operational activities. In addition, scholars have discussed the ability of IT Capability to introduce best practice processes and to aid organisations in transforming their work processes to become more efficient. Indeed, prior studies on IT Capability have reported its significant impact on service process improvement and organisational performance (Chen, 2012; Chen \& Tsou, 2012). Nevertheless, there is limited research on the impact of IT Capability on BPM and SCA. It is vital to examine the impact of IT Capability on processes and competitiveness, as Porter (1985) stated the importance of IT Capability along with key value chain activities in improving organisations' buying power, supplier power, and rival management. In short, IT Capability is only relevant when it is able to create value in developing an organisation's competitive advantage.

\subsection{Relationship between BPM, SCA, and IT Capability}

The dynamic capability theory is the overarching theory for this research. Organisations must understand their internal and external competencies and continuously upkeep the performance of their competencies to survive in such turbulent market conditions (Teece et al., 1997), because organisations with superior dynamic capabilities are able to make their competition irrelevant. An effective BPM can assist in the enhancement of organisational competencies and thus, the development dynamic capabilities. With an effective BPM, the right application of IT Capability enables the efficiency of processes. As a result, an organisation's entire value chain becomes superior, the effect of which can be felt by its employees, suppliers, and customers.

The main objective of this research was to investigate the mediating effect of BPM on the relationship between IT Capability and SCA (Trkman, 2010), based on Nadarajah and Kadir's (2016) suggestion to examine the concept of BPM (comprising BPO and PII) and its impact on SCA (McCormack, 2001; Skrinjar et al., 2008; Trkman, 2010). With respect to IT Capability, scholars have called for future studies to understand the full connection between IT Capability and organisational performance, as well as how IT Capability can be leveraged to increase competitiveness (Aral \& Weill, 2007). Therefore, this study proposed that BPM has a positive impact on SCA and mediates the relationship between IT Capability and SCA.

\section{Part 1 - Quantitative Research}

\subsection{Research Methodology}

The quantitative method was identified as the appropriate approach to empirically test the framework outlined in Figure 1. This research was carried out using a close-ended survey instrument, which enabled the administration of the instrument to a large number of participants. The survey consisted of questions for the constructs for BPM, SCA, and IT Capability rated upon a five-point Likert scale that was anchored from strongly disagree (1) to strongly agree (5). The construct of BPM was measured using (i) BPO, which was obtained from Neubauer (2009), and (ii) PII, which was obtained from Lok et al. (2005). The 
construct measure for SCA was sourced from Gowen and Tallon (2005). Finally, the scale for IT Capability was derived from Aral and Weill (2007). Appendix 1 presents the questionnaire items for this study.

The survey instrument underwent pilot testing on 60 working adults who were either pursuing their MBA in the Faculty of Business and Accountancy in University of Malaya or practitioners employed in the process and quality department of their organisations. Overall, the survey instrument was deemed reliable and achieved the desired consistency in measuring the instrument. Based on the reliability analysis, BPO reported a Cronbach Alpha value of 0.901, PII reported a Cronbach Alpha value of 0.912, SCA reported a Cronbach Alpha value of 0.757 , and IT Capability reported a Cronbach Alpha value of 0.888. According to Hair et al. (2006), measurement scales are considered reliable when a Cronbach Alpha value of 0.700 or above is achieved for each construct.

The survey instrument was then administered to the target respondents. The study was targeted at Malaysian organisations listed under the Malaysia 1000 Directory published by MATRADE and BASIS Publication House Sdn Bhd. This directory contains names and correspondences of 1000 organisations spanning all the states in Malaysia. They were selected because these well-established organisations would have a proper BPM structure and department. All of the 1000 organisations listed were solicited for the study, whereby the CEOs or CFOs of these 1000 companies were contacted and invited to participate in the research. Those who obliged were given the option to complete the survey via online or hardcopy modes. Those who preferred the online medium were sent an email containing a link to the survey, which was developed using Survey Monkey. Meanwhile, those that preferred hardcopies received the survey form via post. All respondents were given two weeks to complete the survey. In an effort to increase the response rate, a follow-up email was sent to the respondents over the two week period as a reminder.

\subsection{Data Analysis}

A total of 274 responses were received. The surveys were checked for completeness, following which 26 were discarded for having more than $50 \%$ of unanswered questions. This yielded a total number of 248 usable responses for analysis. The demographic profile indicated a high proportion of respondents from the services sector $(75 \%)$ as opposed to the manufacturing sector $(25 \%)$. Within the services sector, the highest number of respondents came from the areas of telecommunications (16\%), IT and other consulting practices (11\%), and financial services (13\%). From the manufacturing sector, the highest number of respondents came from the engineering (13\%) field. Overall, most of the respondents came from well-established organisations that have been operating for more than 10 years (46\%).

Based on the analysis, the findings of the study revealed a significant relationship between $\mathrm{BPM}$ and SCA $(\beta=0.653, \mathrm{SE}=0.066, \mathrm{p}$-value $=0.000)$. However, the study failed to observe significant relationships between IT Capability and BPM $(\beta=0.002, \mathrm{SE}=0.104$, $\mathrm{p}$-value $=0.974)$ as well as IT Capability and $\operatorname{SCA}(\beta=0.175, \operatorname{SE}=0.131$, $\mathrm{p}$-value $=0.171)$. 
Hence, the empirical study on the relationship between IT Capability and BPM was unsuccessful in establishing a significant result in the Malaysian context. Interestingly, a similar observation was documented back in 2001 by a study conducted in Singapore (Ranganathan \& Dhaliwal, 2001). These authors discovered that although IT capabilities were employed in organisations, IT expertise was lacking amongst the employees. The observation brought to light the notion that procured IT capabilities suffer challenges when integrating into an organisation's structure and processes. After almost 20 years, it appears that the issue remains prevalent in Malaysia, a close neighbour of Singapore.

These findings were puzzling yet intriguing, as they contradict current literature's emphasis that IT Capability can influence processes and build competitiveness. This mooted the researchers to further investigate this phenomenon to gain an in-depth understanding of the findings. Subsequently, interview sessions were organised to provide deeper perspectives on the phenomenon of IT Capability and its effect on BPM and SCA, with the intention to comprehend why IT Capability failed to display significant relationships with BPM and SCA.

\section{Part 2- Qualitative Research}

\subsection{Research Methodology}

Qualitative research methods in Information Systems (IS) research is not new and has been in practice over the last decade (Myers \& Newman, 2007). As such, in order to provide richer knowledge on the outcomes of IT Capability with regards to BPM and SCA, the structured interview method was employed. Sekaran (2003) suggests that the appropriate number of interview sessions is based on the level of satisfaction reached by the researcher in the outcomes of the interviews. For this study, interviews with three industry experts were deemed sufficient (Eisenhardt, 1989). The ratio of 2:1 interviewees from the services and manufacturing industries was determined to match the respondents' profile in the survey research, which had more than two-thirds of responses from the services industry. From the services sector, the telecommunications and IT consulting fields were selected as these were the top two business natures within the services sector.

One of the main advantages of interviews is its flexibility to adapt questions based on the progress of the interview (Sekaran, 2003). With regards to disadvantages, interviews are subject to bias, which may occur when there is an evident lack of trust and rapport between the interviewer and interviewee. In addition, situational bias occurs due to the physical setting of the interview session (Sekaran, 2003). In an effort to overcome bias, the interviewees were selected from the list of respondents in the survey and the interviews were conducted in their respective office premises at their most convenient time. The interviewees had more than 10 years of work experience and were in senior management roles in their respective organisations. This selection criteria was applied to match the respondents' demographic profile in the prior survey.

Initially, the identified interviewees were contacted and requested to spare 30 minutes of their time to answer some questions. The interview questions were designed to understand the 
potential reasons for IT Capability's lack of influence on BPM and SCA. Accordingly, the questions posed to the interviewees were as follows:

- Is IT Capability crucial in your organisation?

- In what way is IT Capability related to your organisations SCA?

-In what way is IT Capability related to your business processes?

- In my study on Malaysian companies, it was observed that IT Capability was not related to SCA. What is your opinion on this finding about IT Capability within the Malaysian context?

- In my study on Malaysian companies, IT Capability was not related to BPM. What is your opinion on this finding about IT Capability within the Malaysian context?

The interview sessions were recorded with the interviewees' permission and later transcribed for content analysis. All three interviewees requested that their identities and that of their organisations remain anonymous. The requests of the interviewees were respected and as such their identities and the name of their establishments were not revealed in this paper. The feedback from the industry experts were compared with each other and also against sources from literature.

\subsection{Data Analysis}

The first interviewee was from a well-established local telecommunications company operating for more than 15 years. The company has an entire division dedicated towards IT and infrastructure management. The interviewee was a senior official heading the division and was also in the senior management team of the company. The second interviewee was from a manufacturing company established in Malaysia for over 20 years. Similarly, the interviewee was heading the IT and project management division. The third interviewee was from an IT consulting firm operating for over 15 years. The interviewee was the Chief Operating Officer (COO) of the company.

Overall, the services sector viewed top management supervision and employee involvement as critical components to supplement IT Capability. Conversely, in the manufacturing industry, IT Capability was viewed to be optimal as a mechanism for cost reduction instead of as a competency to gain competitive advantage. The insights from the interviewees provided plausible reasons for IT Capability's failure to portray significant relationships with BPM and SCA. The subsequent sections capture the essence of the interview findings, categorised by specific industries.

\subsubsection{Telecommunications Industry}

The telecommunications industry in general relies heavily on IT Capability, which is a necessity in ensuring smooth business operations. One possible reason for the phenomenon observed in the quantitative study is top management's failure to ensure the effectiveness of IT Capability. Top management is aware of the importance of IT Capability and assumes that the capability developed will certainly aid the execution of strategies and thus create SCA. However, the situation at the ground level may be entirely different from what is assumed. A 
main factor that hinders top management's attention to the effectiveness of IT Capability implementation is time constraint. Another possible explanation is the urgency to react quickly to market changes, which indirectly causes improper implementation of IT Capability and, consequently, the lack of SCA creation. This opinion is highly contradictory to the available literature on IT Capability. Chen (2012) and Chen and Tsou (2012) reported that IT Capability has a significant impact on service process improvement and organisational performance. The view point of the interviewee indicates that top management supervision is an integral element for IT Capability to effectively influence BPM and SCA.

IT Capability is procured to adopt best practice processes; however, in reality, organisations tend to focus their efforts on changing new software to match their existing organisational processes. Hence, the rewards of purchasing state-of-the-art software may not materialise. In other cases, due to strong resistance to change, the new software may be severely underutilised. These situations contribute to branding newly-purchased IT Capability as the "white elephant" in an organisation.

Last but not least, the knowledge, skills, and competencies of employees are an equally crucial factor in ensuring the effectiveness of IT Capability implementation. It is recognised that change management is imperative to ascertain that all levels of employees within the organisation understand and work together in realising the new IT Capability's implementation. Although Porter (1985) advocates that IT Capability can influence overall organisational competitiveness, the component of people is critical in assuring the desired outcomes are achieved.

\subsubsection{Manufacturing Industry}

The manufacturing industry's landscape in Malaysia does not rely heavily on IT Capability for their production line. IT Capability is mainly employed in the sales and marketing division and supports the service division. The reason why IT Capability is less emphasised in the production line is due to cost, since it would warrant huge investments and impact production time, thereby indirectly affecting production volume. Employees' productivity hours would also be reduced due to training time and production downtime.

In addition to this, the factor that contributes to SCA in the manufacturing industry is speed-to-market rather than IT Capability. A superior supply chain and the ability to meet production volume with minimal defects are the factors of SCA here. It was mentioned by the interviewee that the production line operates based on extremely efficient processes with lean structures. This opinion is in line with Barney (1991) and Rijamampianina et al. (2003), who state that each organisation carves out different competencies which are harnessed to become a competitive advantage. With respect to the manufacturing industry, speed-to-market and quality are apparently more relevant to achieve competitiveness, while IT Capability's importance is focused on ensuring operational costs are minimal. 


\subsubsection{IT Consulting}

IT consulting is a fast-growing niche industry in Malaysia. IT Capability cannot be separated from the IT consulting world; in fact, it is the core of the sector. Similar to the telecommunications industry, IT Capability in IT consulting is highly regarded by top management. Nevertheless, top management usually lacks the placement of necessary enforcements to ensure strategic plans are executed effectively, though IT Capability is crucial in creating SCA for the industry.

It is not surprising, therefore, that IT Capability failed to display a significant relationship with BPM. This can be attributed to poor direction and alignment from top management, since the mechanisms through which IT Capability is translated to BPM activities are not explicitly communicated and cascaded down. This creates a mismatch between objectives and implementation, which corroborates the opinion of the interviewee from the telecommunications industry.

Another reason for this phenomenon is the overly idealistic strategic objectives that are articulated due to stakeholder pressure or top management's inexperience. This causes the organisation and its employees to suffer in the process of trying to reach and deliver those strategic objectives. When coupled with ineffective feedback loops and realignment, the implementation of IT Capability is doomed for failure. This viewpoint extends that of the first interviewee, validating that top management supervision is important to ensure proper alignment with strategic objectives through efficient monitoring mechanisms.

With regards to objectives, it is also believed that business divisions lack clarity in setting clear requirements, which results in challenges in developing suitable IT Capability. This may result in IT Capability that is procured and developed in-house to be misaligned with BPM operational activities.

\section{Discussion}

The current study was carried out to determine the influence of IT Capability on BPM and SCA. A survey-based quantitative research in the Malaysian business context failed to observe significant relationships between IT Capability and BPM as well as IT Capability and SCA. This motivated qualitative interview sessions to better understand the reasons for such findings. Three interviews were conducted covering the telecommunications, manufacturing, and IT consulting sectors.

According to Chen and Tsou (2012), IT Capability is closely linked to organisation structure and business strategy. The fact is that IT Capability is not self-sufficient and relies on other organisational factors to be effective. Strong IT Capability with weaker counterparts can thus cripple the effectiveness of implementation. One possible challenge in realizing the full benefits of IT Capability on BPM is the complexity and size of legacy systems, as advocated by Lepments et al. (2012). Moreover, Peppard and Ward (2004) and Peak et al. (2011) believe that IT employees' lack of understanding of business goals hampers the effectiveness of IT 
Capability on processes. IT Capability also requires strong IT leadership to create SCA (Lim et al., 2012). This is concurred with by Kearns and Lederer (2003) and Neubauer (2009), who recommend that a mix of business and IT skills is required of the leadership in any organization, which is in line with the findings from the interview sessions in this study.

Kearns and Lederer (2003) also recommend top management to consider being involved in both IT and business planning, to make certain that IT capabilities can be realized alongside strategic business outcomes. Ullah and Lai (2011) explain that the effectiveness of IT Capability is difficult to realize due to rapidly changing internal and external environments. As such, IT Capability should be implemented while taking into consideration the industry's external as well as internal environmental conditions (Stoel \& Muhanna, 2009).

The views of the interviewees are in line with literature as well as with findings from the survey. In short, it is not that IT Capability is irrelevant to organisations. On the contrary, IT Capability had no significant effect on BPM and SCA in this study due to other factors, such as top management oversight, poor employee involvement, strategic misalignment, ineffective monitoring, and organisational culture that hinders the full potential of IT Capability in an organization. The findings from the interview sessions also unearthed the critical role of top management in monitoring the implementation of IT Capability, the effectiveness of communication through change management activities, and the level of competency among IT and non-IT employees. This provides insights to practitioners when implementing IT Capability in their organisations.

\section{Conclusion}

The outcomes of both the quantitative and qualitative aspects of this research have implications for theory and practice. It is noteworthy that there are many factors at play in terms of IT Capability's effectiveness, especially from the people aspect. Future research into IT Capability should examine the influence of factors such as top management support, employee empowerment, and organisational culture. IT practitioners should also be sensitive towards top management commitment and employee empowerment when building IT Capability in organisations. Another interesting point to consider is the degree of IT fluency among top management, as it is a key determinant of the level of support given to IT projects.

With respect to BPM, this research has demonstrated that it has a significant effect on SCA. This denotes that BPM is a unique, rare, and inimitable internal capability which can result in competitive advantage. For this reason, IT Capability must be integrated with BPM with caution. As the interview sessions point out, organisations apply IT Capability to adopt best practice processes, yet may fail to achieve the desired results. As such, IT Capability should be implemented to support or enhance BPM, and not to replace BPM. Further, in light of the industrial revolution 4.0, the concept of BPM and IT Capability can be widened to encompass big data and artificial intelligence. 


\section{Macrothink}

\section{Acknowledgement}

Thank you to the interviewees for spending your time to contribute towards this research endeavor.

\section{References}

Aral, S., \& Weill, P. (2007). IT assets, organizational capabilities, and firm performance: How resource allocations and organizational differences explain performance variation. Organization Science, 18, 763.https://doi.org/10.1287/orsc.1070.0306

Attaran, M. (2004). Exploring the relationship between information technology and business process reengineering. Information \& Management, 41, 585-596. https://doi.org/10.1016/S0378-7206(03)00098-3

Barney, J. (1991). Firm resources and sustained competitive advantage. Journal of Management, 17, 99-119. https://doi.org/10.1177/014920639101700108

Bharadwaj, A. (2000). A resource-based perspective on information technology capability and firm performance: An empirical investigation. MIS Quarterly, 24, 169-196. https://doi.org/10.2307/3250983

Chen, J.-L. (2012). The synergistic effects of IT-enabled resources on organizational capabilites and firm performance. Information \& Management, 49, 142-150. https://doi.org/10.1016/j.im.2012.01.005

Chen, J.-S., \& Tsou, H.-T. (2012). Performance effects of IT capability, service process innovation and the mediating role of customer service. Journal of Engineering and Technology Management, 29, 71-94. https://doi.org/10.1016/j.jengtecman.2011.09.007

Chaharbaghi, K., \& Lynch, R. (1999). Sustainable competitive advantage: Towards a dynamic resource-based strategy. Management Decision, $37,45$. https://doi.org/10.1108/00251749910252012

Eisenhardt, K., M. (1989). Building theories from case study research. Academy of Management Review, 14, 532-550. https://doi.org/10.5465/amr.1989.4308385

Goldkuhl, G., \& Lind, M. (2008). Coordination and transformation in business Processes: Towards an integrated view. Business Process Management Journal, 14, 761-777. https://doi.org/10.1108/14637150810915964

Gowen, C. R., \& Tallon, W. J. (2005). Effect of technological intensity on the relationships among six sigma design, electronic-business, and competitive advantage: A dynamic capabilities model study. Journal of High Technology Management Research, 16, 59-87. https://doi.org/10.1016/j.hitech.2005.06.004

Hair, J. F., Black, W. C., Babin, B. J., Anderson, R. E., \& Tatham, R. L. (2006). Multivariate data analysis (6th ed.). Upper Saddle River, NJ: Pearson Education International. 


\section{Ml Macrothink}

Business Management and Strategy

ISSN 2157-6068

2019, Vol. 10, No. 2

Lee, R. G., \& Dale, B. G. (1998). Business process management: A review and evaluation. Business Process Management Journal, 4, 214. https://doi.org/10.1108/14637159810224322

Lim, J.-H., Stratopoulos, T.C., \& Wirjanto, T.S. (2012). Role of IT executives in the firm's ability to achieve competitive advantage through it capability. International Journal of Accounting Information Systems, 13, 21-40. https://doi.org/10.1016/j.accinf.2011.07.001

Liu, Y., Lu, H., \& Hu, J. (2008). IT capability as moderator between IT investment and firm performance. Tsinghua Science and Technology, 13(3), 329-336. https://doi.org/10.1016/S1007-0214(08)70053-1

Lok, P., Hung, R. Y., Walsh, P., Wang, P., \& Crawford, J. (2005). An integrative framework for measuring the extent to which organizational variables influence the success of process improvement programmes. Journal of Management Studies, 42(7), 1357-1381. https://doi.org/10.1111/j.1467-6486.2005.00547.x

Mccormack, K. (2001). Business process orientation: Do you have it? Quality Progress, 34, 51-58. https://doi.org/10.1201/9781420025569

Myers, M. D., \& Newman, M. (2007). The qualitative interview in IS research: Examining the craft. Information \& Organization, $\quad 17, \quad 2-26$. https://doi.org/10.1016/j.infoandorg.2006.11.001

Nadarajah, D., \& Kadir, S.L. (2014). A review of the importance of business process management in achieving sustainable competitive advantage. The TQM Journal, 26(5), 522-531. https://doi.org/10.1108/TQM-01-2013-0008

Nadarajah, D., \& Kadir, S. L. (2016). Measuring business process management using business process orientation and process improvement initiatives. Business Process Management Journal, 22(6), 1069-1078. https://doi.org/10.1108/BPMJ-01-2014-0001

Neubauer, T. (2009). An empirical study about the status of business process management. Business Process Management Journal, 166-183. https://doi.org/10.1108/14637150910949434

Paim, R., Caulliraux, H. M., \& Cardoso, R. (2008). Process management tasks: A conceptual and practical view. Business Process Management Journal, 14, 694-723. https://doi.org/10.1108/14637150810903066

Porter, M. E. (1985). Technology and competitive advantage. Journal of Business Strategy, 5(3), 60-78. https://doi.org/10.1108/eb039075

Ranganathan, C., \& Dhaliwal, J. S. (2001). A survey of business process reengineering practices in Singapore. Information \& Management, 39, 125-134. https://doi.org/10.1016/S0378-7206(01)00087-8 


\section{Macrothink}

Rijamampianina, R., Abratt, R., \& February, Y. (2003). A framework for concentric diversification through sustainable competitive advantage. Management Decision, 41, 362-371. https://doi.org/10.1108/00251740310468031

Sekaran, U. (2003). Research methods for business: A skill building approach, New York: John Wiley \& Sons Inc.

Skrinjar, R., Bosilj-Vuksic, V., \& Indihar-Stemberger, M. (2008). The impact of business process orientation on financial and non-financial performance. Business Process Management Journal, 14, 738-754. https://doi.org/10.1108/14637150810903084

Stoel, M. D., \& Muhanna, W. A. (2009). IT capabilities and firm performance: A contingency analysis of the role of industry and IT capability type. Information \& Management, 46, 181-189. https://doi.org/10.1016/j.im.2008.10.002

Teece, D. J., Pisano, G., \& Shuen, A. (1997). Dynamic capabilities and strategic management. Strategic Management Journal, 18(7), 509-533. https://doi.org/10.1002/(SICI)1097-0266(199708)18:7<509::AID-SMJ882>3.0.CO;2-Z

Trkman, P. (2010). The critical success factors of business process management. International Journal of Information Management, 30(2), 125-134. https://doi.org/10.1016/j.ijinfomgt.2009.07.003

Zairi, M. (1997). Business process management: A boundary-less approach to modern competitiveness. Business Process Management Journal, $3,64$. https://doi.org/10.1108/14637159710161585

\section{Appendix}

Appendix 1.

1. Constructs for IT Capability are as follows:

- Technical skills of IT staff in the organisation facilitates new technology investments.

- Business skills of IT staff in the organisation facilitates new technology investments.

- IT skills of end users in the organisation facilitates new technology investments.

- Ability to hire new IT staff in the organisation facilitates new technology investments.

- Senior management support for IT projects facilitates new technology investments.

- Business units involvements in IT projects facilitates new IT investments.

- Communication methods such as email, intranets, and wireless devices are important for internal communications within the organisation. 
- Communication methods such as email, intranets, and wireless devices are important for communications with suppliers.

- The organisation has a high degree of digitization in its purchasing process electronic purchase orders / total purchase orders.

- The organisation has a high degree of digitization in its sales process electronic sales / total sales.

- The organisation has a high degree of Internet technology use to perform sales force management.

- The organisation has a high degree of Internet technology use to perform employee performance management.

- The organisation has a high degree of Internet technology use to perform employee training.

- The organisation has a high degree of Internet technology use to perform post-sales customer support.

2. Constructs for BPM are as follows:

BPO:

- The average employee views the business as a series of linked processes.

- Process terms such as input, output, process, and process owners are used commonly in conversations in the organisation.

- Processes within the organisation are defined and documented using inputs and outputs to and from customers.

- Implementation of information technology is based on the processes, not on functions.

- Jobs are usually multidimensional and not just simple tasks.

- Jobs include frequent problem solving.

- People are constantly learning new things on the job.

- Process measurements are clearly defined.

- Process performance is measured in the organisation.

- Resources are allocated based on processes.

- Specific process performance goals are in place.

PII:

- There is an increase in the number of employees involved in process improvement initiatives in the last three years.

- The number of process improvement initiatives has increased annually in the last three years. 
- The organisation has a formal methodology in place to guide process improvement initiatives.

- The organisation will definitely continue with process improvement initiatives.

- The overall experience with process improvement initiatives has generally been positive.

- The process improvement initiatives contribute to bottom line improvement.

3. Constructs for SCA are as follows:

- The available resources and capabilities enable effective response to external threats and opportunities.

- A large part of the organisation's internal resources and capabilities are not possessed by competitors.

- Competitors are likely to face high cost disadvantage to duplicate the organisation's programmes.

- There is vast difference between the organisation's strategic position and the competitors' strategic position.

\section{Copyright}

Copyright for this article is retained by the author(s), with first publication rights granted to the journal.

This is an open-access article distributed under the terms and conditions of the Creative Commons Attribution license (http://creativecommons.org/licenses/by/4.0/). 